\title{
Ileal Band
}

National Cancer Institute

\section{Source}

National Cancer Institute. Ileal Band. NCI Thesaurus. Code C101276.

A pathologic fibrous band that impedes passage of intestinal contents through the ileum. 